\title{
Understanding of Irritable Bowel Syndrome among General practitioners in the Periphery of Lahore
}

\author{
ATIF MASOOD ${ }^{1}$, FAISAL AMIN BAIG ${ }^{2}$, TAHIR ULLAH KHAN ${ }^{3}$, NASEEB UR REHMAN SHAH ${ }^{4}$, MAIDA NAZIR ${ }^{5}$, WALI $^{2}$ \\ $\mathrm{KHAN}^{6}$ \\ ${ }^{1,2}$ Associate Professors, ${ }^{3}$ Assistant Professor, ${ }^{5}$ Senior Registrar, Department of Medicine University of Lahore Teaching Hospital Lahore \\ ${ }^{4}$ Assistant Professor Medicine Khalifa Gul Nawaz Teaching Hospital/MedicalCollege Bannu \\ ${ }^{6}$ Senior RegistrarHepatobiliary Unit Shaikh Zayed Teaching Hospital Lahore \\ Correspondence to: Dr Tahir Ullah Khan, Email: tahirnurar69@gmail.com, Cell: 0332-9930269
}

\begin{abstract}
Objective: To determine the understanding of irritable bowel syndrome among general practitioners in Lahore in terms of diagnosis and treatment.

Study Design: Observational, cross sectional study.

Place and Duration of Study: Department of Medicine, University of Lahore Teaching Hospital, Lahore from $1^{\text {st }}$ October 2020 to $31^{\text {st }}$ March 2021.

Methodology: Two hundred and ninety eight patients from both urban and rural territory in Lahore were enrolled. Manning and Rome criteria were applied to establish diagnosis of irritable syndrome. Patient's history, investigations and final diagnosis were recorded. After three months, patients were reassessed for final diagnosis and any alternative diagnosis if under consideration.

Results: There were $180(60.4 \%)$ females and 118 (39.6\%) males with mean age of 34 years. About 70 patients presented with GIT complains were functional and 45 with organic problems. Out of 70 functional patients, 45 have irritable bowel syndrome. The condition was functional or organic quite inadequate and amounted to $56 \%$. Conclusion: Majority of irritable bowel syndrome patients were either wrongly diagnosed by the general practitioners or inadequately treated.

Key words: Irritable bowel syndrome (IBS), Functional and organic diarrhea.
\end{abstract}

\section{INTRODUCTION}

Irritable bowel syndrome or disease is a functional disorder of gastrointestinal tract characterized by troublesome abdominal pain relieved by defecation and sense of incomplete evacuation. Gastrointestinal tract is the primary source of reactive oxygen species (ROS) which play a key role in normal metabolic pathways and normal functioning of gut. The two essential components of normal human metabolism are reactive nitrogen species (RNS) and reactive oxygen species (ROS) and any changes in these two components can result in catastrophic consequenceswith primary pathophysiology being oxidative stress. ${ }^{1}$ The possible association of oxidative stress with numerous known gastrointestinal disorders including IBS and pathologies including premature ageing phenomenon, cardiovascular and kidney injuries, malignancy, and neuropathic disorders like Alzheimer's disease. ${ }^{2}$ Apart from gastrointestinal tract, brain is a strong source of reactive oxygen species (ROS). The complex interaction between gut and brain results in functional gut disorders like irritable bowel syndrome. ${ }^{3}$ In fact, many of the functional GIT pathologies originate from such over responsive oxidative modulation, which is known as oxidative stress. ${ }^{4}$ Studies reveal that chronic gut inflammation is strongly linked with excessive generation of reactive oxygen and nitrogen species. ${ }^{5}$ Additionally, some studies have shown that inflammation is generally a key component of the GIT diseases. ${ }^{6-8}$

Human body particularly gastrointestinal tract is inhabited by approximately 39 trillion microbial cells resulting in generation of a dynamic, perfectly scrutinized ecological environment famously termed as the microbiota. The microbiota consists of viruses, bacteria, fungi and protozoa, constituting about 20 million genes. ${ }^{9,10}$ Microbiota and the ecological environment are critical to the maintenance of a health and functional gut exerting important functions such as energy extraction from different nutrients, metabolizing xenobiotics, controlling gut motility and keeping epithelial barrier intact. ${ }^{11}$ It is now recognized worldwide thatconstituents and function of gut microbiota potentially contribute to the pathophysiology of functional Gl disorders.

Irritable bowel syndrome (IBS) is the most common and well recognized of all the functional gut disorders and generally poorly understood by the general practitioners in terms of diagnosis and management. The purpose of the current study is to determine the pitfalls on behalf of general physicians while diagnosing and managing irritable bowel syndrome.

\section{MATERIALS AND METHODS}

This observational cross-sectional studywas conducted at Department of Medicine, University of Lahore Teaching Hospital, Lahore from $1^{\text {st }}$ October 2020 to $31^{\text {st }}$ March 2021.Two hundred and ninety-eightpatients from both urban and rural territory in Lahore were enrolled.A brief history of the patient was taken,those patients who consented for the research were asked for a brief interview about their visit and any other complaint.Patients were asked about the main complaint for which they visited the doctor, and any other related complaint was also noted.After a brief interview, those patients who had a GIT complaint were screened out, consent was taken and with their permission their previous medical record was also explored. Patient was requested to fill a questionnaire which had been validated previously by the experts of the field. To establish the diagnosis of IBS or functional bowel habits Manning and Rome criteria was followed. The same 
team member than interviewed the doctor about the concerned patient. A separate questionnaire was used concerning the history of the patient, investigations, and final diagnoses. After three months another visit was made to the doctor, the record of the patient was reviewed, and the best possible diagnoses were made from all the available resources. If there was a discrepancy, new diagnosis was concluded using index complaints about functional disorder of GIT complaints. Rome or Manning criteria were applied to diagnose Irritable bowel syndrome. The data was entered and analyzed through SPSS-24.

\section{RESULTS}

There were 180 (60.4\%) were female and 118 (39.6\%) male with mean age of 34 years. Only $45 \%$ were labelled as irritable bowel syndrome while the rest were wrongly diagnosed as acid peptic disease not responding to standard treatment (24.8\%), intestinal tuberculosis (14.7\%), inflammatory bowel disease $(7.7 \%)$, nonspecific colitis (7.4\%) and intestinal malignancy (0.4\%) [Table 1]. Among the $45 \%$ patients rightly diagnosed as irritable bowel syndrome by the general practitioners, only 65\% were treated according to the standard protocols (Table 2). Among irritable bowel syndrome patients, a number of variations were noted in terms of symptomatology. Majority of the patients presented with abdominal pain (55\%) followed by constipation (20\%), diarrhea (15\%), nonspecific epigastric discomfort (10\%), bloating $(8 \%)$ as illustrated in figure 1.

Table 1: Diagnosis of different diseases $(n=298)$

\begin{tabular}{|l|l|l|}
\hline Disease & No. & $\%$ \\
\hline Functional (IBS) & 134 & 45.0 \\
\hline Acid peptic disease & 74 & 24.8 \\
\hline Intestinal tuberculosis & 44 & 14.7 \\
\hline Inflammatory bowel disease & 23 & 7.7 \\
\hline Nonspecific colitis & 22 & 7.4 \\
\hline Intestinal malignancy & 1 & 0.4 \\
\hline
\end{tabular}

Table 2: Right versus wrongly treated IBS patients $(n=134)$

\begin{tabular}{|l|l|l|l|}
\hline Variable & No. & $\%$ & P value \\
\hline Right treatment given & 87 & 65.0 & \multirow{2}{*}{0.0001} \\
\cline { 1 - 3 } Wrongly treated & 47 & 35.0 & \\
\hline
\end{tabular}

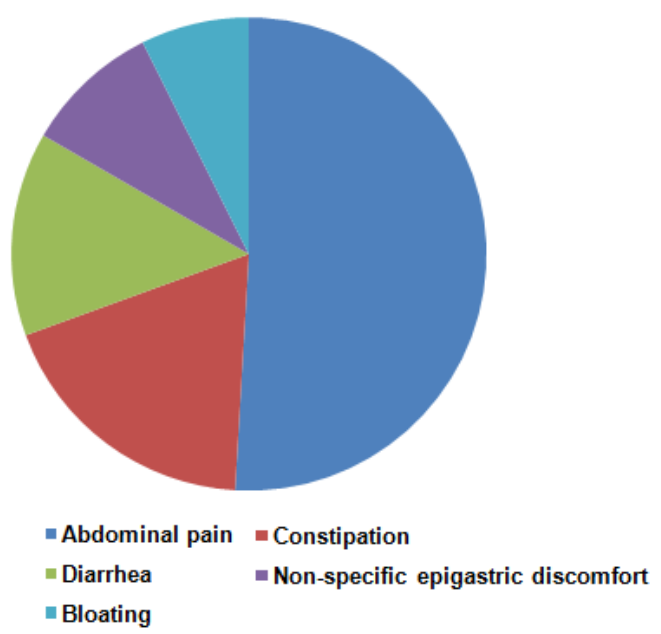

Fig. 1: Different presentation of IBS
Table 3: Various responses of patient with IBS and Organic disease

\begin{tabular}{|l|l|l|l|}
\hline Patient response & $\begin{array}{l}\text { Organic } \\
\text { disease }\end{array}$ & IBS & $P$ value \\
\hline Serious disease phobia & 20 & 27 & 0.084 \\
\hline Cancer phobia & 15 & 23 & 0.04 \\
\hline Fear of untreatable disease & 14 & 23 & 0.04 \\
\hline Relieve of symptoms after first visit & 25 & 13 & 0.004 \\
\hline Increase in symptoms with stress & 21 & 30 & 0.004 \\
\hline Absence from duty due to symptoms & 12 & 8 & 0.258 \\
\hline Disturbed social life & 26 & 32 & 0.247 \\
\hline
\end{tabular}

The phobia about some serious problem outnumbered in patients with IBS as compared with patients with some organic problemwith $p$ value 0.084 . Similarly, the phobia of cancer in IBS is far more than patients with some organic disease with $p$ value $<0.04$. Patients with IBS have a fear that they are not going to recover which is more than patients with organic disease. After first visit to the family physician patients with organic disease showed remarkable improvement as compared to patients with IBS with $p$ value $<0.004$, same value is reflected in patients with IBS who showed increased in their symptoms under stress as compared to patients with organic disease (Table 3).

\section{DISCUSSION}

The symptoms observed by the patients with IBS are diverse. In our study, majority of the patients manifested as abdominal pain $(55 \%)$ and constipation $(20 \%)$. This data is similar to a study conducted by Neri et al ${ }^{12}$ and Hammer et al where abdominal pain was found in $50 \%$ of the cases closely followed by diarrhea (20\%) rather than constipation as in our case. ${ }^{13}$ Another study conducted in Egypt by Ahmed et al $^{14}$ reported that $52 \%$ patients had diarrhea alternating with constipation, results slightly different than our study.In another study conducted by Rubin et al ${ }^{15}$ results favored the current study $(45 \%$ patients had abdominal discomfort) in terms of percentage but $\mathrm{p}$ [atients described it as annoyance rather than typical pain. The major reason being that at this level the number of patients attended by the family physician is quite large and they don't spare much time to these patients who also have some added psychological problems, while studying the comorbidities (OR 1.22) and sleep disorders (OR 5.40), the conclusion drawn by Norlin et $\mathrm{al}^{16}$ supported our study. Once such screening is done patients either continue with the treatment offered by the family physician or they themselves decide to seek attention from a specialist physician. However, a small group of patients are referred to specialist by the family physician who feels that such patients should have an expert opinion, a study conducted in 2016 by Williams et $\mathrm{al}^{17}$ and another study conducted by Bellini et $\mathrm{al}^{18}$ supports the present study.

Present study confirms that GIT complains are one of the leading cause of attending family physiciansand majority $(45 \%)$ of these complaints are functional rather than organic. Similar results (55\%) were found in a study conducted by Camilleri et $\mathrm{al}^{19}$ and a study conducted in 2015 by Schmid et $\mathrm{al}^{20}$ supports current study with nearly half $(50 \%)$ being functional.

In the present study, IBS patients had serious disease phobia in 27 subjects (9\%), cancer phobia in 23 subjects $(7 \%)$ and fear of untreatable disease in 23 subjects $(7 \%)$. Almost similar percentage with a slight difference of $12 \%$ patients having cancer phobia was found in a study 
conducted by Blomhoff $S$ et al. $^{21}$ In the present study, general physicians were able to correctly diagnose IBS in $45 \%(n=134)$ cases whereas $55 \%(n=164)$ were having wrong diagnoses. These findings coincide with studies conducted by Vyas $^{22}$ (45\% wrongly diagnosed, slightly lower than our study) and Al-Shamrani et al ${ }^{23}$ (50\% wrongly diagnosed ) in Saudi Arabia. All the family physicians in the present study are making final diagnosis of IBS through their back ground knowledge or the experience they have gained with time, a study conducted in 2019 by BrownLieberson ${ }^{24}$ supports the present study. However, despite all the shortcomings on the part of general practitioners, Rangan et $\mathrm{al}^{25}$ Ballou and Lembo ${ }^{26}$ observed a significantly high percentage $(80 \%)$ of patients had satisfaction about their diagnosis and treatment, a finding above the scope of the present study and potential topic for research in future on possible causes of such high patients satisfaction rate. Also, the treatment offered to such patients is benefiting these patients also but in a different way, this theory put forward by Simrén and Tack ${ }^{27}$ and Enck and Mazurak needs further research and interogation. ${ }^{28}$

To address the causes of wrong diagnosis and treatment of IBS by the general practitioners, Mahmoudi et al reported that system failure in providing general practitioners proper training and medical education, inability on the part of general practitioners to keep pace with latest updates and variations in patient's history are the possible contributors. ${ }^{29}$ The present study, although, did not focus on possible causes, but it did pave a way for further research on the topic.

\section{CONCLUSION}

Majority of IBS patients were either wrongly diagnosed by the general practitioners or inadequately treated.

\section{REFERENCES}

1. Salim S. Oxidative stress and psychological disorders. CurrNeuropharmacol2014;12:140-47.

2. Padurariu M, Ciobica A, Lefter R, Serban IL, Stefanescu C, Chirita R. The oxidative stress hypothesis.

3. Martin HM, Hancock JT, Salisbury V, Harrison R. Role of xanthine oxidoreductase as an antimicrobial agent. Infect Immun 2004;72:4933-9.

4. Borody TJ, Brandt LJ, Paramsothy S. Therapeutic faecal microbiota transplantation: Current status and future developments. CurrOpin Gastroenterol 2014;30:97-105.

5. Wendland BE, Aghdassi E, Tam C, Carrrier J, Steinhart AH, Wolman SL, Baron D, et al. Lipid peroxidation and plasma antioxidant micronutrients in Crohn disease. Am J Clin Nutr2001;74:259-64.

6. Damiani CR, Benetton CAF, Stoffel C, Bardini KC, Cardoso VH, Di Giunta S, et al. Oxidative stress and metabolism in animal model of colitis induced by dextran sulfate sodium. $J$ Gastroenterol Hepatol 2007;22:1846-51.

7. Olliver JR, Hardie LJ, Gong Y, Dexter S, Chalmers D, Harris $\mathrm{KM}$, et al. Risk factors, DNA damage, and disease progression in Barrett's esophagus. Cancer Epidemiol Biomarkers Prev2005;14:620-25.

8. Lim YJ, Lee JS, Ku YS, Hahm KB. Rescue strategies against non-steroidal anti-inflammatory drug-induced gastroduodenal damage. J Gastroenterol Hepatol 2009;24:1169-78.

9. Sender R, Fuchs S, Milo R. Revised estimates for the number of human and bacteria cells in the body. PLoSBiol 2016; 14:e1002533.
10. Schulberg J, De Cruz P. Characterisation and therapeutic manipulation of the gut microbiome in inflammatory bowel disease. Internal Med J 2016; 46: 266-73.

11. Fava F, Danese S. Intestinal microbiota in inflammatory bowel disease: friend of foe? World J Gastroenterol 2011; 17: 557-66.

12. Neri M, Laterza F, Howell S, Di Gioacchino M, Festi D, Ballone $\mathrm{E}$, et al. Symptoms discriminate irritable bowel syndrome from organic gastrointestinal diseases and food allergy. Eur J Gastroenterol Hepatol 2000;12(9):981-8.

13. Hammer J, Eslick GD, Howell SC, Altiparmak E, Talley NJ. Diagnostic yield of alarm features in irritable bowel syndrome and functional dyspepsia. Gut 2004;53(5):666-72.

14. Ahmed A, Mohamed RA, Sliem HA, Eldein HN. Pattern of irritable bowel syndrome and its impact on quality of life in primary health care center attendees, Suez governorate, Egypt. Pan Afr Med J 2011;9(1).

15. Rubin G, Wit ND, Meineche-Schmidt V, Seifert B, Hall N, Hungin $P$. The diagnosis of IBS in primary care: consensus development using nominal group technique. Family Prac 2006;23(6):687-92.

16. Norlin A-K, Faresjö Å, Falk M, Jones MP, Walter S. Primary healthcare utilisation and self-rated health among patients with Irritable bowel syndrome: what are the impacts of comorbidities, gastrointestinal symptom burden, sense of coherence and stress? J Psychosomatic Res 2019;119:1-7.

17. Williams M, Barclay Y, Benneyworth R, Gore S, Hamilton Z, Matull $R$, et al. Using best practice to create a pathway to improve management of irritable bowel syndrome: aiming for timely diagnosis, effective treatment and equitable care. Frontline Gastroenterol 2016;7(4):323-30.

18. Bellini M, Usai-Satta $P$, Bove A, Bocchini R, Galeazzi F, Battaglia $E$, et al. Chronic constipation diagnosis and treatment evaluation: the "CHRO. CO. DI. TE" study. BMC Gastroenterol 2017;17(1):1-11.

19. Camilleri M, Boeckxstaens G. Dietary and pharmacological treatment of abdominal pain in IBS. Gut 2017;66(5):966-74.

20. Schmid J, Langhorst J, Gaß F, Theysohn N, Benson S, Engler $\mathrm{H}$, et al. Placebo analgesia in patients with functional and organic abdominal pain: a fMRI study in IBS, UC and healthy volunteers. Gut 2015;64(3):418-27.

21. Blomhoff S, Spetalen S, Jacobsen MB, Malt UF. Phobic anxiety changes the function of brain-gut axis in irritable bowel syndrome. Psychosom Med 2001;63(6):959-65.

22. Vyas K. Irritable Bowel Syndrome (IBS)-a Family Physician's Perspective. Indian Practitioner 2018;71(12):2932.

23. Al-Shamrani HAA, Khalil $\mathrm{H}$, Khan MS. Awareness and Utilization of ROME Criteria for Diagnosis of Inflammatory Bowel Syndrome among Primary Care Physicians in Riyadh, Saudi Arabia. Materia Socio-medica 2020;32(2):112.

24. Brown-Lieberson S. Attitudes and knowledge about irritable bowel syndrome (IBS) among family medicine physicians and IBS patients [Dissertation]. 2019.

25. Rangan V, Ballou S, Shin A, Camilleri M, Nee J, Iturrino J, et al. Use of Treatments for Irritable Bowel Syndrome and Patient Satisfaction Based on the IBS in America Survey. Gastroenterology 2020;158(3):786-8. e1.

26. Ballou S, Lembo A. symptom improvement does not equal satisfaction with treatment for constipation. Wiley Online Library; 2020.

27. Simrén M, Tack J. New treatments and therapeutic targets for IBS and other functional bowel disorders. Nature Rev Gastroenterol Hepatol 2018;15(10):589-605.

28. Enck P, Mazurak N. Dysbiosis in functional bowel disorders. Ann NutrMetab2018;72(4):296-306.

29. Mahmoudi L, Shafiekhani M, Dehghanpour H, Niknam R. Community pharmacists' knowledge, attitude, and practice of Irritable Bowel Syndrome (IBS): the impact of training courses. Advan Med EducPrac2019;10:427 